\title{
O Barão da Ralé: O Mito Madame Satã e a identidade nacional brasileira
}

PAULA LACERDA*

\author{
ROCHA, Gilmar. \\ O Rei da Lapa: Madame Satã e a Malandragem Carioca. \\ Uma história de violência no Rio de Janeiro dos anos 30-50. \\ Rio de Janeiro: 7 Letras, 2005.
}

\begin{abstract}
"Chapéu-de-panamá, terno de linho branco, calça boca-de-chorro, camisa de seda [...], sapato duas cores com salto carrapeta, anéis nos dedos e navalha no bolso. Mulato, andar estilo meiode-banda, exímio capoeirista, filho de Exu ou protegido de São Jorge [...], mestre no samba, gigolô...”
\end{abstract}

(p. 11).

A trajetória da vida de João Francisco dos Santos, nos anos em que surge e se consolida o personagem Madame Satã, é retratada com riqueza de detalhes na obra do antropólogo Gilmar Rocha. A versão revisada de sua dissertação de mestrado, intitulada $O$ Rei da Lapa, reúne um útil conjunto de fontes sobre Madame Satã, Lapa e malandragem. Com o intuito de situar os significados da malandragem para seus membros constituintes - e também para quem simplesmente a via passar - Rocha utiliza em sua análise não somente a biografia de Satã, mas também histórias narradas por sambistas, crônicas literárias da época e letras de canções de ao menos três décadas. A reunião do material a ser analisado, realizada de forma pouco usual porém criativa, foi feita de forma a possibilitar a investigação simultânea dos significados do ser/sentir-se malandro e o que ela representava a outros olhares - tanto para sambistas simpáticos ao grupo quanto para os responsáveis por coagi-la.

A proposta do livro ultrapassa a compreensão da malandragem a partir do lendário Madame Satã, que para alguns é o próprio constituinte desse jeitinho de enfrentar a polícia, brigar na rua, burlar o trabalho e viver de expedientes. Seguindo a perspectiva dos estudos da cultura popular, o autor indica que a malandragem fornece pistas para a reflexão sobre aspectos da sociedade brasileira, tais como a violência, a honra, a valentia e a malícia, inseridos em 
contexto de classes populares. É em torno desses quatro eixos que o autor circunscreve a malandragem carioca.

No entanto, antes de prosseguir com as contribuições da obra, assinalamos que os elementos em que se pauta sua construção metodológica ampliam e inovam a visão da Antropologia Social e dos estudos da cultura popular; por isso nas linhas que se seguem desenvolveremos alguns dos principais instrumentos metodológicos operacionalizados.

Já foi dito que Madame Satã pode ser compreendido como um personagem. Para além do fato de ele ter sido considerado mitômano (alguns de seus relatos de prisão referem-se a períodos em que não esteve preso, alguns dos crimes que toma para si foram executados por outros malandros etc.), as histórias sobre a malandragem apresentam-se similares e agregadas, compondo uma narrativa plural, mas que basicamente conflui para os mesmos pontos.

A opção do autor por interpretar os acontecimentos estruturantes da malandragem (especialmente a lenda de que um único soco de Madame Satã, proferido depois de ter sido chamado de "viado", teria levado à morte o sambista Geraldo Pereira) como mito-história abarca a perspectiva de que ficção e realidade se confundem nessa narrativa caracterizada pela polifonia. Desta maneira, os "acontecimentos paradigmáticos" que estruturam o imaginário sobre a malandragem são definidos pelo autor como histórias de malandros sobre malandros que ultrapassam os fatos episódicos para espelharem elementos da cultura brasileira.

A história da morte de Geraldo Pereira, em especial, combina elementos de natureza moral, econômica, social, sexual, compondo o que o autor identifica como uma teia de significados. O conceito, emprestado do antropólogo Clifford Geertz (1998), indica que os indivíduos são os "tecedores" das teias que compõem sua própria cultura. Esta, por sua vez, pode se tornar inteligível para pesquisadores a partir de situações cotidianas como uma piada ou uma brincadeira, e também através de "sistemas culturais", como a arte e a música. O sentido privilegiado por Rocha destaca a maneira paradigmática pela qual valentia, honra, (homos)sexualidade e violência se encontram inseridas nesse evento. Acionando pontos em comum, esses símbolos constituem a teia de significados da cultura brasileira. Além disso, o fato de a briga entre dois famosos malandros ter-se tornado um mito inúmeras vezes repetido demonstra também a importância desse evento como um possível feixe das "teias" da malandragem. Assim, tornou-se um acontecimento que revela os códigos culturais vigentes, além de 
prescrever a visão de mundo e estilos de vida desejáveis para os próprios malandros.

O ponto inicial das proposições sobre honra feitas por Gilmar Rocha baseia-se nos estudos de Pitt-Rivers sobre a sociedade mediterrânea. Aproximase destes na medida em que o modelo de honra vigente na malandragem tem seu arcabouço no campo da sexualidade. A moral dos homens, neste sentido, se vincula à sua virilidade e à pureza sexual das mulheres que o circundam. No entanto, o autor vai mais além. Reconstituindo a conjuntura histórica do Brasil na primeira metade do século XIX, podemos acompanhar as mudanças que o país atravessava e a possível maneira que estas afetaram a construção da malandragem.

A reforma de Pereira Passos na cidade do Rio de Janeiro, a caça aos "vadios", a recente abolição da escravatura e o surgimento de uma "Ciência Criminal" foram fatores decisivos na conformação da personalidade do malandro como sujeito erradio e perigoso aos olhos da lei. O livro indica a pluralidade de possibilidades de interpretações da malandragem, que podia ser vivida (e entendida) como drible ao trabalho ou como ideologia que visava a escarnecer o poder do Estado.

A contextualização de classe também é uma preocupação do autor, que vincula os códigos morais da malandragem ao ethos das classes populares. Desta maneira, a disposição para a briga, a esperteza, a constante afirmação da honra e da identidade não são atributos exclusivos do malandro, mas pertencem também ao grupo no qual ele está inserido. Essa perspectiva é bastante interessante, por sugerir que o malandro não deva ser interpretado exclusivamente como um marginal, mas como um sujeito que compartilha os valores de determinado grupo social, chegando mesmo a representá-lo. Assim, ainda que indigno aos olhos do Estado, poderia ser, aos olhos do povo, um sujeito vigilante e honrado. Segundo o autor, "o homem pobre e marginalizado encontra no estilo de vida do malandro o sentido público de sua cidadania. Na república da malandragem, paradoxalmente, o malandro tornar-se-ia rei" ( $\mathrm{p}$. 57 - grifos no original).

A hipótese levantada pelo autor é condizente com a preocupação em contextualizar os eventos da vida de Madame Satã e seus significados no escopo da cultura popular da época: o malandro tradicional, bem como a própria malandragem, representados na figura de perigosos capoeiras e inimigos do 
Estado desaparecem na medida em que a modernização do país é fomentada pelo Governo Juscelino Kubitschek. A individualização, como sua consequiência, proporcionou a morte do malandro enquanto representante das classes populares para transformar-se em símbolo cultural domesticado. A Lapa cede espaço para Copacabana, o samba para a bossa-nova.

A reconstrução histórica dos significantes da malandragem revela a maneira pela qual eles foram ajustados às mudanças sociais em curso ao longo das décadas. Nesse sentido, as referências disponibilizadas na obra são convincentes na afirmação de que o eixo das representações sobre a malandragem desloca-se da violência para pousar sobre a burla ao trabalho ou, em momento posterior, ao mero caráter estereotípico de sua pessoa (ou seja, a transformação do malandro em figura ficcional, domesticada).

Gilmar Rocha menciona que a autoconstrução do malandro se organiza a partir de sua relação com o bairro da Lapa, sua valentia e sua homossexualidade. No entanto, é ausente no texto o significado da homossexualidade para o próprio Madame Satã. A perspectiva de que parte o autor assinala que a relação entre malandragem/violência e homossexualidade é contraditória. Do ponto de vista dos habitués da Lapa, dos policiais e demais malandros, poderia ser esta a opinião sustentada, mas, a partir dos relatos de Madame Satã, não temos a sensação de que sua homossexualidade seja vivenciada em descompasso à sua malandragem.

Por fim, mencionamos que a caça a prostitutas, homossexuais, mendigos e negros mencionada pelo autor poderia vir cotejada com o percurso dos ideais eugenistas no Brasil. A disseminação de medidas que objetivavam a "melhoria da raça" iniciou-se no Brasil com a fundação da Sociedade Eugênica de São Paulo em 1918, mas estiveram presentes até o fim do Governo Vargas (STEPAN, 2004) - período no qual se localiza grande parte das prisões de Madame Satã.

Desta forma, os eventos narrados por Satã são fortemente modulados pelas políticas de Vargas, que vinculava cidadania ao trabalho e, conseqüentemente, acossava os que se encontravam fora dessa esfera. Homossexuais, prostitutas e delinqüentes pertenciam ao grupo dos "problemas sociais" a serem combatidos pelo Estado Novo. Completando o quadro dos acontecimentos históricos da época, citamos a criação do Instituto de Identificação, em 1933, onde o médico legista Leonídio Ribeiro realizou um estudo de Antropologia Criminal em 195 "pederastas passivos" fichados pela Polícia Civil do Rio de Janeiro (RIBEIRO, 1938). 
A obra é um precioso instrumento aos leitores que procuram as tão escassas informações sobre Madame Satã. A contribuição teórica sobre cultura de classe, símbolos da identidade nacional brasileira, significados da violência e da honra são bastante relevantes. No entanto, a grande contribuição se dá pelo exemplo de trabalho criativo e bem-feito que manipula habilmente diferentes categorias de fontes de pesquisa, tendo com pano de fundo acontecimentos políticos e sociais da história do Brasil.

\section{Referências}

GEERTZ, C. A interpretação das culturas. Rio de Janeiro: Zahar, 1998.

RIBEIRO, L. Homossexualismo e endocrinologia. Rio de Janeiro: Francisco Alves, 1938.

STEPAN, N. L. Eugenia no Brasil, 1917-1940. In.: HOCHMAN, G.; ARMUS, D. (Orgs.). Cuidar, controlar, curar: ensaios sobre a saúde e doença na América Latina e Caribe. Rio de Janeiro: Fiocruz, 2004. p. 331-391.

\section{NOTA}

\footnotetext{
* Mestranda em Saúde Coletiva, Programa de Pós-graduação em Saúde Coletiva do Instituto de Medicina Social da Universidade do Estado do Rio de Janeiro. Endereço eletrônico: lacerda@ims.uerj.br.
} 